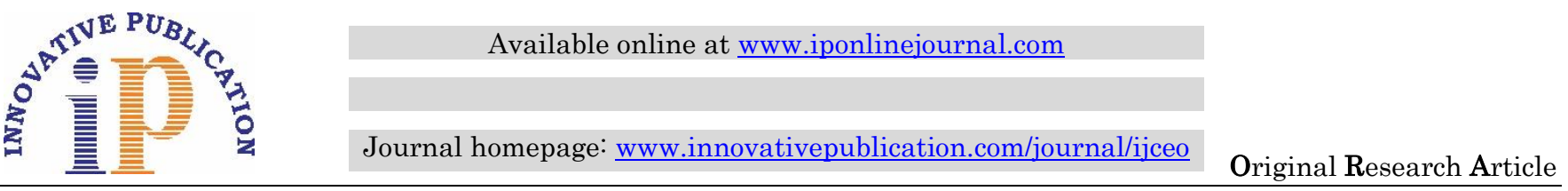

\title{
Serum electrolytes in cataract patients with and without diabetes: A case control study
}

\author{
Gona Soujanya ${ }^{1}$, Inchara $\mathrm{N}^{2 *}$, Kanthamani $\mathrm{K}^{3}$ \\ ${ }^{1}$ Resident, ${ }^{\mathbf{2}}$ Assistant Professor, ${ }^{3}$ Professor, Dept. of Ophthalmology, Sri Devaraj Urs Academy of Higher Education and Research, Kolar, \\ Karnataka, India
}

\section{Article Info}

Received: $27^{\text {th }}$ March, 2019

Accepted: $31^{\text {st }}$ May, 2019

Published Online: $9^{\text {th }}$ September, 2019

Keywords: Cataract, Diabetes, Dyselectrolemia, Serum electrolytes.

\begin{abstract}
Introduction: Cataract is the cloudiness of the lens causing dispersion of light so as to cause significant optical disturbance. Cataract development occurs more frequently and at a younger age in diabetics compared to nondiabetic patients. Aqueous acts as an ocular lymph which is analogous to serum. So any dyselectrolemia which is common in diabetics can cause water and cationic imbalance in the lens resulting in cataract formation.

Materials and Methods: This case-control study was done with 75 diabetic and 75 nondiabetic cataract subjects, by comparing the serum electrolytes of both the groups. Statistical analysis was done using SPSS version 21. Student's unpaired ' $t$ ' test was used to compare the means of electrolytes. Regression analysis and Odd's ratio was calculated to study the association between electrolytes and the risk of cataractogenesis.

Result: Significant rise in serum Na+, K+ and Cl- levels $(\mathrm{p}<0.0001,<0.0286,<0.0001$ respectively) were observed in diabetics compared to nondiabetic cataracts. This rise in electrolytes will pose $1.4,1.8,1.17$ times $(\mathrm{Na}+, \mathrm{K}+$ and $\mathrm{Cl}$ - respectively) higher odds of early formation of cataract in diabetics compared to nondiabetics.

Conclusion: This study concludes and validates the increased risk of cataractogenesis in diabetics when compared to non-diabetics as shown by other studies. Also reflected the significant difference in the serum electrolytes in comparison with the non-diabetics. Thus indicating the dietary restriction of salt in diabetics which hasten the onset and progression of cataract.
\end{abstract}

\section{Introduction}

Cataract is the leading cause of preventable blindness worldwide, contributing to $80 \%$ of treatable blindness in India. Though there are many risk factors identified for cataract genesis, the exact pathogenesis is not yet established. ${ }^{1}$ Lens in its anatomical site remains in constant contact with aqueous humour. It is a clear fluid, an ultrafiltration of serum acts as an analogue of the blood. Any biochemical changes in the aqueous humour disrupts the lens fibres and cause loss of transparency. ${ }^{2,3}$

Diabetes Mellitus is associated with various biochemical changes in the blood like dyselectrolemias, impaired renal function, and acid-base disorders due to insulin deficiency, malabsorption syndromes etc. ${ }^{4}$ Though there are many causes of vision loss in diabetics, the cataract is the leading cause. Polyol pathway regulates the sorbitol and glucose in the lens leading to lenticular opacity. ${ }^{5,6}$ Few studies in this view have showed the significantly higher values of serum electrolytes in diabetic cataracts than the non-diabetics, and their risk in cataract progression. ${ }^{7,8}$

However, there are limited studies exploring on this issue in Indian settings to the best of our knowledge. The purpose of this study is to estimate serum electrolytes in cataract patients with type 2 diabetes as compared to the cataract patients without diabetes. As cataract is one among the treatable causes of blindness, it is justifiable to make an attempt to identify a probable risk factor for the cataractogenesis.

\section{Objectives}

1. To estimate and compare the serum electrolyte levels in Type 2 diabetes and non-diabetic patients with cataract.

2. To determine the serum electrolyte abnormality as a risk factor for cataract development.

\section{Materials and Methods \\ Source of Data}

This prospective case control study was conducted in R.L.J. Hospital and Research Centre, Tamaka, Kolar attached to Sri Devaraj Urs Medical College for 3 months between September 2018 to November 2018. We included 150 patients with cataract scheduled for surgery meeting the inclusion and exclusion criteria from the ophthalmology outpatient department.

\footnotetext{
*Corresponding Author: Inchara N, Assistant Professor, Dept. of Ophthalmology, Sri Devaraj Urs Academy of Higher Education and Research, Kolar, Karnataka, India

Email: dr.inchara@gmail.com

http://doi.org/10.18231/j.ijceo.2019.098
} 


\section{Data Collection}

After the informed consent is taken from the patient, detailed history with reference to the visual symptoms, duration of the diabetes was taken in particular to meet the exclusion criteria. Participants were subjected to slit lamp examination to grade the cataract according to LOCS II (lens opacities classification system). They were categorised into two commonest groups as mixed cataracts (PSC, cortical cataract, NS) and nuclear sclerosis cataracts. Further indirect ophthlmoscope fundus examination with was done to know the posterior segment findings. All the routine investigations which are to be done for a cataract patient with diabetes such as serum creatinine, blood urea, glycated haemoglobin, fasting blood sugars, post-prandial blood sugars were done.

75 type 2 Diabetics of age $>40 y r$ with cataract were taken as cases (group A) and 75 age, sex matched non diabetic cataract participants (group B) as controls. Cataract patients were sampled into cases and controls by using convenience sampling based on the past history and RBS reports (new cases). Five $\mathrm{ml}$ of venous blood sample was collected by puncturing antecubital vein with aseptic precautions and were sent to the central laboratory. Samples were centrifuged at $3000 \mathrm{rpm}$ and was analysed for electrolytes by potentiometric method in dry chemistry analyser vitros 5.1 FS. Blood glucose and $\mathrm{HbAlc}$ were estimated by Glucose oxidase-peroxidase method and immunoturbidimetric method respectively.

\section{Inclusion Criteria}

Group A-Type 2 diabetes mellitus Patients of age $>40 y r s$ with cataract.

Group B- Age \& sex matched non-diabetics with cataract.

\section{Exclusion Criteria}

Patients with complicated cataract, Liver disorders, Hypertension, Renal disorders, Thyroid disorders and infections, those with sustained trauma, Patients on oral steroids, Alcoholics and smokers.

\section{Statistical Analysis}

The data were entered into MS Excel 2010 version and further analyzed using SPSS 20ver. Categorical variables like sex, type of cataract were represented using percentage and proportion. Continuous variables like age, serum electrolytes values were analyzed using mean \pm standard deviation. Tests of significance was carried with ' $t$ ' test and Chi square test. Logistic regression was used to study the association between serum electrolytes in diabetic and nondiabetics and "p" $<0.05$ was considered as statistically significant.

\section{Results}

Mean age of cataract participants was $63.3 \pm 8$ years ranging from 40 years to 85 years. $47 \%$ were females and $53 \%$ were males. Mean duration of diabetes mellitus was $5 \pm 3$ years ranging from new case to 20 years. Both mixed cataracts and nuclear sclerosis cataract were $49 \%$ and $48 \%$ respectively. Further Nuclear Sclerosis (NS) was graded and $28 \%$ of the patients had grade 2 NS. The mean serum sodium value was $146 \pm 2.5 \mathrm{mEq} / \mathrm{l}$ and $143 \pm 2.8 \mathrm{mEq} / \mathrm{l}$; mean potassium levels were $4.4 \pm 0.8 \mathrm{mEq} / \mathrm{l}$ and $4.2 \pm 0.6 \mathrm{mEq} / 1$, mean chloride levels were $95 \pm 5.7 \mathrm{mEq} / \mathrm{l}$ and $90 \pm 5.3 \mathrm{mEq} / \mathrm{l}$ in cases and controls respectively as shown in the table $1 \&$ 2. Mixed cataracts and nuclear sclerosis cataract were found equally distributed among both the groups. But mean age at which the visually significant cataract in diabetics was found to be 60 years and 65 years in non-diabetics as in table 3 .

\section{Discussion}

According to WHO, India will become one of the major hubs of diabetic population over the next 2 decades, with the number of diabetics increasing from 8 million in 1995 to 80 million in 2030. ${ }^{9,10}$

Previous epidemiologic studies have established several risk factors for the development of senile cataracts including age, diabetes mellitus, serum electrolyte changes, obesity, smoking, and low socioeconomic status (SES) ${ }^{8,9}$

Dysnatremias are a result of various mechanisms operating in Diabetes mellitus. Both hypo and hypernatremia are reported in diabetics. Normal Serum sodium is a result of equilibrium between dilutional hyponatremia and hypernatremia due to glycosuria induced osmotic diuresis. Disturbance of equilibrium of water and electrolytes disturbs colloid system within lens fibers leading to opacification of lens. ${ }^{11}$ There is greater incidence of hyperkalemia in diabetics due to shift of potassium to extracellular compartment, whereas hypokalemia in diabetics is attributed to insulin administration which causes redistribution of potassium to intracellular compartment.

Various theories have been put forward for cataractogenesis in diabetics. Adler, described aqueous humour as 'ocular lymph' as its electrolyte concentration varies with varying plasma concentration, in turn leading to changes in lens transparency. ${ }^{11}$

In our study we have found the mean sodium, potassium and chloride levels in the serum were significantly high with $\mathrm{p}$ value $<0.0001,<0.0286,<0.0001$ in group A when compared with group B subjects. As per our observation the raise of $\mathrm{Na}^{+}, \mathrm{K}^{+}, \mathrm{Cl}^{-}$in serum would increase the risk of cataract formation up to the levels (table 2 ) which is statistically significant $(\mathrm{p}<0.0001)$.

It was also found that mean age of patients from group $\mathrm{A}$ and group B was 60 years and 65 years with $\mathrm{p}$ value $<0.006$ presenting with visually disabling cataract, which is statistically very significant.

The Framingham Eye Study and the Health and Nutrition Examination Survey (HANES), both showed a marked excess prevalence of senile cataract in diabetics less than 65 years old (relative risks of 4.02 and 2.97, respectively). Beyond the age of 64 years, the HANES study but not the Framingham study showed an excess prevalence, although it was less marked (relative risks of 1.63 and 1.02, respectively). ${ }^{12}$ 
The risk increases with the longer duration of diabetes and with poor metabolic control. The most frequently seen type of cataract in diabetics is the age related or senile.

Table 1: Comparison of $\mathrm{Na}^{+}, \mathrm{K}^{+}$and $\mathrm{Cl}^{-}$between diabetic and non -diabetic cataract patients $(\mathrm{n}=150)$

\begin{tabular}{|c|c|c|c|}
\hline \multirow{2}{*}{ Group } & Diabetic & \multirow{2}{*}{ p-value } \\
\cline { 2 - 3 } & \multicolumn{2}{|c|}{ Mean mEq/I (SD) } & $<\mathbf{0 . 0 0 1} *$ \\
\hline $\mathbf{N a}^{+}$ & $146.1(2.5)$ & $143.4(2.85)$ & $\mathbf{0 . 0 2 9 7} *$ \\
\hline $\mathbf{K}^{+}$ & $4.4(0.08)$ & $4.2(0.04)$ & $<\mathbf{0 0 1} *$ \\
\hline $\mathbf{C l}^{-}$ & $95.8(0.7)$ & $90.6(0.6)$ & \\
\hline
\end{tabular}

$(* \mathrm{p}<0.05$ is statistically significant)

Table 2: Logistic Regression Analysis of $\mathrm{Na}^{+}, \mathrm{K}^{+}$and CI level between diabetic and non -diabetic cataract patients

\begin{tabular}{|c|c|c|c|c|}
\hline Independent Variables & \multirow{2}{*}{ Odds ratio } & \multicolumn{2}{|c|}{$\mathbf{9 5 \%}$ Confidence intervals } & \multirow{2}{*}{ 'p' Value } \\
\cline { 3 - 4 } & & Lower & Upper & \\
\hline $\mathrm{Na}^{+}$ & 1.4 & 1.25 & 1.72 & $<0.001 ; \mathrm{S}$ \\
\hline $\mathrm{K}^{+}$level & 1.8 & 1.05 & 3.16 & $0.032 ; \mathrm{S}$ \\
\hline $\mathrm{CI}^{-}$level & 1.17 & 1.10 & 1.25 & $<0.001 ; \mathrm{S}$ \\
\hline
\end{tabular}

$\mathrm{S}$ - Significant, NS- Not significant

Table 3: Comparison of age of patients with cataract in diabetic and non -diabetic patients

\begin{tabular}{|c|c|c|c|}
\hline Group & Mean age patients with significant cataract & \multicolumn{2}{|c|}{$95 \%$ Confidence intervals } \\
\cline { 3 - 4 } & & Lower & Upper \\
\hline Diabetic & 60 & 59 & 62 \\
\hline Non-diabetic & 65 & 63 & 57 \\
\hline Difference & -5 & -6 & -1 \\
\hline
\end{tabular}

$\mathrm{P}<0.0006$. Significant

variety, which tends to occur earlier and progresses more rapidly than in non-diabetics. ${ }^{13,14}$

Study by Choudhury et al. ${ }^{15}$ reported an elevated serum and aqueous humor sodium and chloride as well as hyperkalemia in diabetic cataract patients.

The changes of serum sodium, potassium and chloride level in nondiabetic cataract cases are in accordance with the studies by, Tasneem A F et al $^{14}$ and Gaurav Mathur et al, ${ }^{16}$ Adiga U et al, ${ }^{17}$ Usha S. Adiga et al. ${ }^{18}$

\section{Conclusion}

This study concludes that there is a significant rise in serum $\mathrm{Na}^{+}, \mathrm{K}^{+}$and $\mathrm{Cl}^{-}$in diabetic patients in comparison with nondiabetics. This attributes to significant risk for development of cataract early in age and its rapid progression. In this view the diabetics who are not only screened for diabetic retinopathy should also be subjected to thorough slit lamp examination to identify the early cataract. Identifying the early cataract in younger age can reverse the process when tackled with multidisciplinary approach like good metabolic control, life style modification, water intake, dietary intake/restriction of the salts etc.

\section{Source of Funding: None.}

Conflict of Interest: None.

\section{References}

1. Barber GW. Physiological chemistry of the eye. Arch Ophthalmol. 1973;89(3):236-55.

2. Sires B. Orbital and ocular anatomy. In: Wright editor. Textbook of Ophthalmology. Baltimore, MD: Williams and Wilkins; 1997.

3. Miller C, Kaufman PL. Aqueous humour: secretion and dynamics, In: TasmanW, Jaeger EA, editiors. Duane e's foundations of clinical ophthalmology. Philadelphia: Lippincott-Raven; 1995.

4. Elisaf MS, Tsatsoulis AA, Katopodis KP, Siamopoulos KC, Acid-base and electrolyte disturbances in patients with diabetic ketoacidosis. Diabetes Res Clin Pract 1996;34:23-7.

5. Wild S, Roglic G, Green A, Sicree R, King H. Global prevalence of diabetes: estimates for the year of 2000 and projections for 2030. Diabetes Care. 2004;27:1047-53.

6. Luntz MH, Clinical types of cataract. Duanee"s Clinacal Ophthalmology. Philadelphia: Lippincott-Raven publishers, 2005;5-7.

7. Hammond CJ, Duncan DD, Snieder H. The heritability of agerelated cortical cataract: the twin eye study. Invest Ophthalmol Vis Sci. 2001;42:601-5)

8. Meyer $\mathrm{CH}$, Sekundo W. Nutritional supplementation to prevent cataract formation. Dev Ophthalmol.2005;38:103-19.

9. Kitabchi A.E, Umpire G.E, Murphy M.B, KriesbergRA. Hyperglycemic crisis in adult patients with diabetes. A consensus statement from American diabetes association. Diabetes Care. 2006;2739-48.

10. Bae JH, Shin DS, Lee SC, Hwang IC. Sodium Intake and Socioeconomic Status as Risk Factors for Development of Age-Related Cataracts: The Korea National Health and Nutrition Examination Survey. Plos one 2015;10(8);e0136218.doi; 10.1371/journal.pone.0136218). 
11. Liamis G, Liberopoulos E, Barkas F, and Elisaf M, "Diabetes mellitus and electrolyte disorders" World J Clin Cases. 2014;2(10):488-96.

12. Kahn HA, Leibowitz HM, Ganley JP, "The Framingham eye study. II. Association of ophthalmic pathology with single variables previously measured in the Framingham heart study," Am J Epidemiol. 1977;106(1):33-41.

13. Mirsamadi M, Nourmohammadi I, Imamiam M. Comparative study of serum $\mathrm{Na}+$ and $\mathrm{K}+$ levels in senile cataract patients and normal individuals. Int J Med Sci. 2004;1:165-9.

14. Tasneem AF, Shwetha BA, Mamata N, "Comparative study of serum and aqueous humour electrolyte levels in cataract patients", Int J Recent Trends Sci Technol. 2014;12(3):507-13.

15. Choudhury RB, Partha Sarathi G, Das B, Comparative study of serum and aqueous humour electrolytes in diabetic and nondiabetic cataract patients. IOSR JDMS. 2016;15(4):1-6.
16. Mathur G, Pai V, Comparison of serum sodium and potassium levels in patients with senile cataract and age-matched individuals without cataract. Indian J Opthalmology. 2016;64:446-7.

17. Adiga U, Malawadi BN. Alterations in serum electrolytes in type 2 diabetes mellitus. Adv Lab Med Int. 2016;6(3):58-62.

18. Adiga US, Harris A. Serum Electrolytes in Cataract Patients with and without Diabetes Mellitus. IJBCRR 2017;19(3):1-5.

How to cite this article: Soujanya G, Inchara N, Kanthamani $\mathrm{K}$, Serum electrolytes in cataract patients with and without diabetes: A case control study. Indian J Clin Exp Ophthalmol. 2019;5(3):407-10. 